\title{
Features of eddy-current testing of the fatigue degradation of laser clad cobalt-nickel-chromium coating under contact loading
}

\author{
R. A. Savrai ${ }^{\dagger, 1}$ L. Kh. Kogan², A. V. Makarov², N. N. Soboleva ${ }^{1}$ \\ †ras@imach.uran.ru \\ ${ }^{1}$ Institute of Engineering Science, UB RAS, 34 Komsomolskaya St., Yekaterinburg, 620049, Russia
${ }^{2}$ M. N. Miheev Institute of Metal Physics UB RAS, 18 S. Kovalevskaya St., Yekaterinburg, 620108, Russia
}

\begin{abstract}
The fatigue spalling due to contact stresses is one of the main types of failure of the surface protective coatings. Therefore, an important task is to study the contact endurance and to develop nondestructive techniques for testing of the fatigue degradation of such coatings. The possibility of using the eddy-current technique to test the fatigue degradation under contact loading of the cobalt-nickel-chromium PG-10K-01 coating obtained through a gas-powder laser cladding has been investigated. It has been shown that the eddy-current testing of the fatigue degradation under contact loading of the PG-10K-01 coating is possible, but has certain limitations due to non-monotonic changes in the eddy-current device readings a depending on the number of loading cycles. While on the one hand, it is possible to test a sharp increase in the size of contact damages, which, under the used loading conditions, occurs after $5 \times 10^{4}$ and $5 \times 10^{5}$ cycles and results from the formation of a large number of peripheral ring cracks in the failure zone and the corresponding decrease in the value of $\alpha$ due to the increasing resistivity of the coating. On the other hand, it is possible to test the achievement of a certain number of loading cycles in the range of $8 \times 10^{5}-1 \times 10^{6}$, when the eddy-current device readings exceed the initial values. This increase in the value of $\alpha$ is caused by the compaction of the coating as a result of healing of discontinuities and a decrease in its resistivity. The testing can be performed by measuring the eddy-current device readings at high excitation frequencies of the-eddy current probe $f=72-120 \mathrm{kHz}$. In this case, the impact of the ferromagnetic steel base on the eddy-current device readings is minimal and mainly surface layers are analyzed, where the processes of crack formation, mechanical hardening, and compaction that affect the physical characteristics of the coating are developed more intensively.
\end{abstract}

Keywords: laser cladding, cobalt-nickel-chromium coating, structure, contact fatigue, eddy-current method.

\section{Особенности вихретокового контроля усталостной деградации наплавленного лазером кобальтхромоникелевого покрытия при контактном нагружении}

\author{
Саврай Р. А. ${ }^{\dagger,}$, Коган Л. Х. ${ }^{2}$, Макаров А. В. ${ }^{2}$, Соболева Н.Н. ${ }^{1}$ \\ ${ }^{1}$ Институт машиноведения, УрО РАН, ул. Комсомольская, 34, Екатеринбург, 620049, Россия \\ ${ }^{2}$ Институт физики металлов им. М. Н. Михеева, УрО РАН, ул. С. Ковалевской, 18, Екатеринбург, 620108, Россия
}

Для защитных покрытий усталостное выкрашивание от контактных напряжений является одним из основных видов разрушения поверхности. Поэтому актуальной задачей является изучение контактной выносливости и разработка способов неразрушающего контроля усталостной деградации таких покрытий. Исследована возможность использования вихретокового метода для контроля усталостной деградации при контактном нагружении кобальтхромоникелевого покрытия ПГ-10К-01, полученного методом газопорошковой лазерной наплавки. Показано, что контроль вихретоковым методом усталостной деградации при контактном нагружении покрытия ПГ-10К-01 возможен, однако имеет определенные ограничения вследствие немонотонного изменения показаний вихретокового прибора а от числа циклов нагружения. При этом с одной стороны, возможен контроль резкого роста размера контактных повреждений, который при данных условиях нагружения происходит при $5 \times 10^{4}$ и $5 \times 10^{5}$ циклов, и обусловлен образованием большого количества периферийных кольцевых трещин в зоне разрушения 
и соответствующим снижением величины а вследствие роста удельного электросопротивления покрытия. С другой стороны, возможен контроль достижения определенного числа циклов нагружения в диапазоне $8 \times 10^{5}-1 \times 10^{6}$, когда показания вихретокового прибора превысят исходные значения. Данный рост величины $\alpha$ обусловлен уплотнением покрытия в результате залечивания несплошностей и уменьшением его удельного электрического сопротивления. Контроль может проводиться измерениями показаний вихретокового прибора на больших частотах возбуждения вихретокового преобразователя $f=72-120$ кГц. В этом случае степень влияния ферромагнитной стальной основы на показания вихретокового прибора минимальна и анализируются преимущественно поверхностные слои, в которых более интенсивно развиваются процессы трещинообразования, механического наклепа, и уплотнения, оказывающие влияние на физические характеристики покрытия.

Ключевые слова: лазерная наплавка, кобальтхромоникелевое покрытие, структура, контактная усталость, вихретоковый метод.

\section{1. Введение}

Сплавы на основе кобальта часто используются как износо- и коррозионностойкие материалы для бессмазочных систем или для работы при повышенных температурах [1-4]. Покрытия из сплавов, содержащих кобальт, по сравнению с безкобальтовыми покрытиями [5], обладают повышенной жаростойкостью, более высокой пластичностью [3] и износостойкостью [4]. При этом кобальт несколько снижает коррозионную стойкость покрытий при обычных температурах, поскольку является более активным металлом, чем никель $[3,4]$. Существуют кобальтовые сплавы различных систем легирования, среди которых наиболее широко распространены сплавы систем $\mathrm{CoCrWC}$ и $\mathrm{CoCr}(\mathrm{W} / \mathrm{Mo})(\mathrm{Ni} / \mathrm{Fe}) \mathrm{C}$ с добавлением кремния и бора (стеллиты) [6-8]. Однако следует отметить, что в последнее время наблюдается общемировая тенденция к уменьшению содержания кобальта в составе покрытий, обусловленная высокой стоимостью кобальта. Экономно легированные составы с меньшим содержанием кобальта представлены, например, сплавами систем CoNiCrBSi и CoNiCrW.

Для защитных покрытий усталостное выкрашивание от контактных напряжений является одним из основных видов разрушения поверхности. Поэтому важным критерием работоспособности покрытий является их способность выдерживать контактные нагрузки [9], которую, как правило, оценивают по характеру разрушения после однократного или повторяющегося (циклического) нагружения поверхности инденторами различной формы [10-23]. В отличие от стеллитов, в литературе имеется не так много работ, посвященных исследованию структуры и свойств кобальтхромоникелевых покрытий из сплавов систем CoNiCrBSi [24] и $\mathrm{CoNiCrW}$ [25-28]. При этом практически отсутствуют работы по исследованию возможности неразрушающего контроля структурного состояния и свойств таких покрытий [27]. В литературе также отмечается, что для контроля свойств металлических сплавов с низкой магнитной проницаемостью целесообразно использование вихретокового метода $[29,30]$.

Целью работы явилось исследование возможности использования вихретокового метода для контроля усталостной деградации при контактном нагружении покрытия ПГ-10К-01, полученного методом газопорошковой лазерной наплавки.

\section{2. Методика исследований}

В качестве материала для создания покрытия был использован порошок марки ПГ-10К-01 (кобальтхромоникелевый сплав системы $\mathrm{CoNiCrW}$ ), содержащий в мас.\%: $1.45 \mathrm{C} ; 22.6 \mathrm{Cr} ; 31.8 \mathrm{Ni}$; $1.2 \mathrm{Fe} ; 1.1 \mathrm{Si} ; 1.6 \mathrm{~B}$; $4.1 \mathrm{~W}$; остальное Сo) гранулометрического состава 40-160 мкм. Наплавку порошка на пластины из стали Ст3 проводили $\mathrm{CO}_{2}$-лазером непрерывного действия при мощности излучения $1.4-1.6 \mathrm{kBT}$, скорости 160-200 мм/мин, расходе порошка 2.9-4.9 г/мин, размере лазерного пятна на поверхности $6 \times 1.5 \mathrm{mм}$. Порошковая смесь транспортировалась в зону наплавки инертным газом (аргоном) при давлении 0.5 атм. Для уменьшения поверхностных напряжений наплавка осуществлялась в два прохода путем наложения одного слоя на другой. При использованном режиме наплавки толщина покрытия составила 1.7 мм. Для устранения волнистости наплавленная поверхность подвергалась шлифованию с интенсивным охлаждением. Толщина покрытия после шлифования составила 0.9-1.1 мм.

Механические испытания на контактную усталость проводили на сервогидравлической установке Instron 8801 с использованием специальной оснастки оригинальной конструкции [31] по схеме пульсирующего неударного контакта «шар-плоскость» с изменением нагрузки в цикле по периодическому (синусоидальному) закону, диаметром стального шара 12.7 мм, предварительной нагрузкой $P_{0}=0.1 \mathrm{\kappa H}$, максимальной нагрузкой $P_{\max }=8.7 \mathrm{\kappa H}$, частотой нагружения $f=35$ Гц на базе $N=10^{6}$ циклов нагружения. Для контакноусталостных испытаний использовали изготовленные из наплавленных пластин прямоугольные образцы размером $85 \times 10 \times 5$ мм. При заданном количестве циклов нагружения проводили не менее двух испытаний. В качестве критериев для оценки стойкости покрытия в условиях циклического воздействия индентора использовали изменение размера пятна контакта на поверхности стали в зависимости от числа циклов нагружения $[10,14-16,18,21,22]$, и появление трещин по контуру пятна контакта $[15,16,18,21,22]$.

Структуру и фазовый состав покрытия, а также поверхности пятен контакта после контактно-усталостных испытаний изучали с применением сканирующего электронного микроскопа Tescan VEGA II XMU с системой рентгеновского энергодисперсионного микроанализа INCA ENERGY 450. Исходную структуру 
покрытий изучали на металлографических шлифах после травления реактивом следующего состава: 40 г $\mathrm{Cu}_{2} \mathrm{SO}_{4}+100$ мл $\mathrm{HCl}+10$ мл $\mathrm{HNO}_{3}+90$ мл $\mathrm{C}_{2} \mathrm{H}_{5} \mathrm{OH}$. При таком травлении металлическая основа покрытия вытравливается значительно сильнее, чем упрочняющие фазы, в результате чего поверхность шлифа приобретает ярко выраженный рельеф, удобный для последующего металлографического анализа.

Измерение электромагнитных параметров выполняли на лабораторном макете вихретокового прибора с использованием дифференциально включенных накладных трансформаторных вихретоковых преобразователей с выступающим стержневым ферритовым сердечником (Рис. 1). Преобразователь с выступающим стержневым сердечником обеспечивает возможность проводить измерения на криволинейных участках, в том числе на пятнах контакта, образующихся на поверхности покрытия после контактно-усталостных испытаний. Локальность контроля использованного вихретокового преобразователя составляет около 3 мм в диаметре. Определяли показания вихретокового прибора а при частотах возбуждения преобразователя $f=36,72,96$ и 120 кГц. Показания вихретокового прибора а прямо пропорциональны ЭДС, наведенной в измерительной катушке вихретокового преобразователя, и являются комплексным параметром, поскольку определяются значениями начальной магнитной проницаемости $\mu_{i}$ и удельного электрического сопротивления $\rho$ объекта измерения $\alpha \sim\left(\mu_{i} \cdot \rho\right)^{-1 / 2}$ [32]. При данной схеме измерений, величина $\alpha=0$ дел. соответствует стандартному образцу, положительные значения а свидетельствуют о росте, а отрицательные значения а свидетельствуют об уменьшении сигнала вихретокового преобразователя. Величину показаний вихретокового прибора а находили как среднее арифметическое из 5-6 измерений. Абсолютная погрешность измерений величины $\alpha$ составила $\Delta \alpha= \pm 3$ дел. Для исследования влияния кривизны поверхности на показания вихретокового прибора, на поверхности исследованных покрытий изготавливали лунки, соответствующие по размерам и глубине пятнам контакта. Измерения на этих лунках и поверхности покрытия без лунок показали, что значения параметра а отличаются не более чем на 5\% при $f=96-120$ кГц, 7.5\% при $f=72$ кГц и $9 \%$ при $f=36$ кГц.

\section{3. Результаты и их обсуждение}

В результате двухслойной лазерной наплавки порошка ПГ-10К-01 на поверхности пластины из стали Ст3 формируется кобальтхромоникелевое покрытие (Рис. 2) со средней микротвердостью поверхности 810 30 HV0.1. Исследование фазового состава с использованием микрорентгеноспектрального анализа (Табл. 1) показало, что металлическую основу покрытия составляет пересыщенный $\gamma$-твердый раствор на основе $\mathrm{Ni}$ и $\mathrm{Co}$ и эвтектика, состоящая из $\gamma$-фазы и борида $\mathrm{CoB}$, a упрочняющими фазами являются карбид $\mathrm{Cr}_{23} \mathrm{C}_{6}$ и карбоборид $\operatorname{Cr}(\mathrm{B}, \mathrm{C})$ [28]. Отметим, что в структуре наплавленных лазером покрытий, как правило, также присутствует некоторое количество несплошностей округлой формы диаметром 2-5 мкм, образовавшихся, по-видимому, в результате газонасыщения материала при наплавке $[17,19]$.

В процессе контактно-усталостных испытаний на поверхности покрытия ПГ-10К-01 образуются пятна

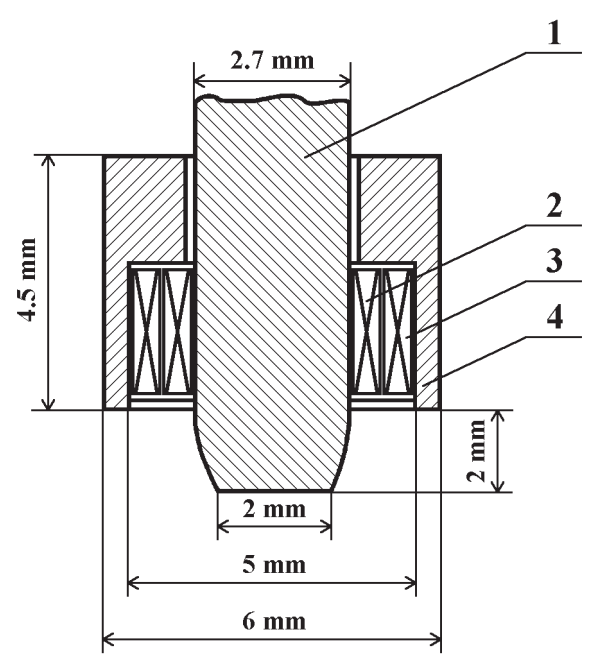

Рис. 1. Схематическое изображение накладного трансформаторного вихретокового преобразователя (1 - выступающий стержневой ферритовый сердечник; 2 - измерительная катушка; 3 - катушка возбуждения; 4 - сердечник броневого типа).

Fig. 1. Schematic representation of attachable transformer eddycurrent probe $(1-$ protruding rod-type ferrite core; $2-$ sensing coil; 3 - excitation coil; 4 - pot-type core).

Табл. 1. Результаты энергодисперсионного микроанализа наплавленного лазером кобальтхромоникелевого покрытия ПГ-10К-01 для участков, указанных на Рис. 2.

Table 1. EDS microanalysis results of the laser clad cobalt-nickel-chromium PG-10K-01 coating for the points illustrated in Fig. 2.

\begin{tabular}{|c|c|c|c|c|}
\hline \multirow{2}{*}{$\begin{array}{c}\text { Элемент } \\
\text { Element }\end{array}$} & \multicolumn{4}{|c|}{ Содержание, мас.\% / Content, wt.\% } \\
\cline { 2 - 5 } & Участок 1 / Point 1 & Участок 2/ Point 2 & Участок 3 / Point 3 & Участок 4 / Роint 4 \\
\hline $\mathrm{Cr}$ & 15.68 & 19.33 & 48.04 & 62.25 \\
\hline $\mathrm{Ni}$ & 37.15 & 29.03 & 13.41 & 6.75 \\
\hline $\mathrm{Co}$ & 35.71 & 35.99 & 24.31 & 16.93 \\
\hline $\mathrm{Fe}$ & 6.75 & 5.14 & 4.15 & 3.85 \\
\hline $\mathrm{C}$ & 0.71 & 1.64 & 2.57 & 3.38 \\
\hline $\mathrm{B}$ & - & 3.72 & -55 & - \\
\hline $\mathrm{Si}$ & 1.42 & - & 4.98 & 4.01 \\
\hline $\mathrm{W}$ & 2.58 & 5.15 & & \\
\hline
\end{tabular}




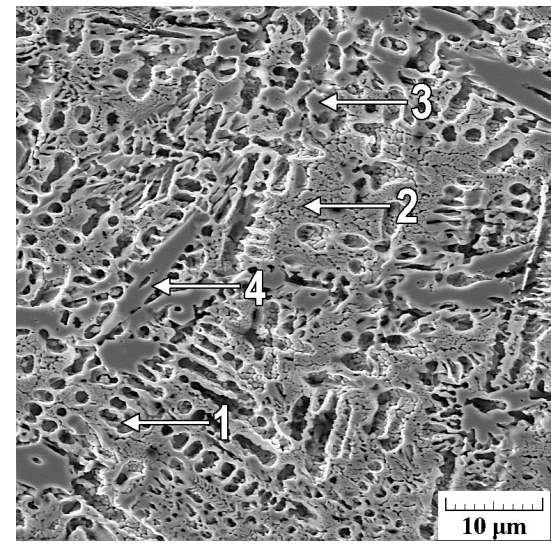

Рис. 2. Микроструктура наплавленного лазером кобальтхромоникелевого покрытия ПГ-10К-01 (1- $\gamma$-фаза; $2-\gamma+\mathrm{CoB}$; $\left.3-\mathrm{Cr}_{23} \mathrm{C}_{6} ; 4-\mathrm{Cr}(\mathrm{B}, \mathrm{C})\right)$.

Fig. 2. Microstructure of the laser clad cobalt-nickel-chromium PG-10K-01 coating $\left(1-\gamma\right.$-phase; $2-\gamma+\mathrm{CoB} ; 3-\mathrm{Cr}_{23} \mathrm{C}_{6}$; $4-\mathrm{Cr}(\mathrm{B}, \mathrm{C}))$.

контакта. Диаметр пятна контакта после $10^{4}$ циклов нагружения составляет 2.09 мм (Рис. 3). С увеличением числа циклов контактного нагружения до $5 \times 10^{4}$, диаметр пятна контакта возрастает до 2.19 мм. Дальнейшее нагружение до $3 \times 10^{5}$ циклов сопровождается стабилизацией диаметра пятна контакта. При числе циклов нагружения $5 \times 10^{5}$ наблюдается резкий рост диаметра пятна контакта до 2.3 мм, а при увеличении числа циклов нагружения от $5 \times 10^{5}$ до $10^{6}$ снова наблюдается стабилизация размера контактных повреждений (см. Рис. 3).

Электронномикроскопическое исследование пятен контакта (Рис. 4) показало, что в процессе контактноусталостного нагружения исследованного покрытия развиваются процессы трещинообразования, характеризующиеся возникновением многочисленных кольцевых и радиальных трещин, а также процессы фреттингизноса. Кольцевые трещины (указаны стрелками 1 на Рис. 4), возникающие на поверхности покрытия в периферийной области пятна контакта - зоне действия максимальных растягивающих радиальных напряжений, способствуют снятию остаточных напряжений внутри покрытия [14] и когезионному разрушению (скалыванию покрытия у края лунки, см. Рис. 4). Когезионное скалывание ослабленного трещинами поверхностного слоя покрытия и обуславливает отмеченный ранее резкий рост диаметра пятна контакта при $5 \times 10^{4}$ и $5 \times 10^{5}$ циклах контактного нагружения.

Фреттинг-износ характеризуется появлением вблизи краев пятен контакта характерных темных участков (указаны стрелками 2 на Рис. 4), представляющих собой оксидные пленки, площадь которых увеличивается с ростом числа циклов нагружения. Наблюдаемые процессы фреттинг-износа исследованного кобальтхромоникелевого покрытия не оказывают существенного влияния на уровень контактных повреждений поверхности при данных условиях контактно-усталостного нагружения [28].

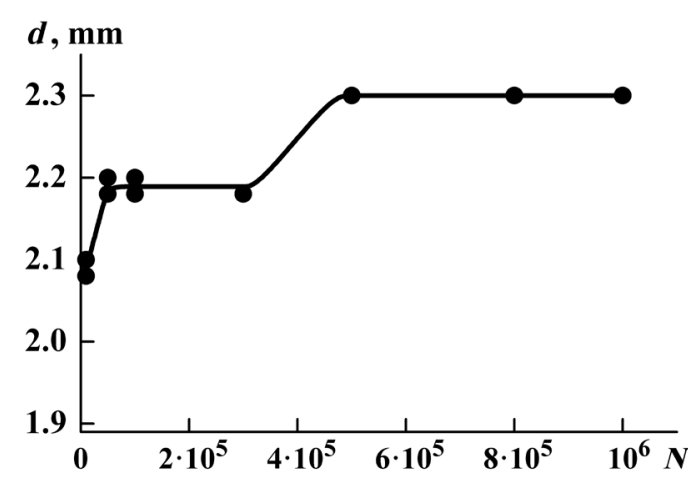

Рис. 3. Влияние числа циклов нагружения $N$ на изменение диаметра пятна контакта $d$ после контактно-усталостных испытаний кобальтхромоникелевого покрытия ПГ-10К-01.

Fig. 3. Influence of the number of loading cycles $N$ on the contact spot diameter $d$ after contact fatigue tests of the cobalt-nickelchromium PG-10K-01 coating.

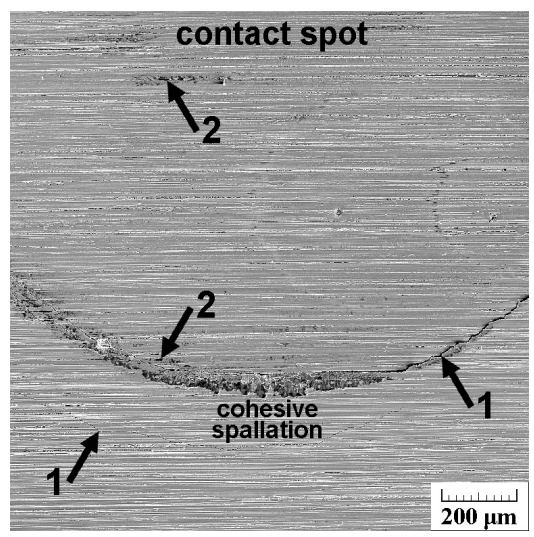

Рис. 4. Пятно контакта (электронная сканирующая микроскопия) после контактно-усталостных испытаний с числом циклов нагружения $N=5 \times 10^{4}$ кобальтхромоникелевого покрытия ПГ-10К-01 (1 - кольцевые трещины; 2 - участки фреттинг-износа).

Fig. 4. Contact spot (scanning electron microscopy) after contact fatigue tests with the number of cycles $N=5 \times 10^{4}$ of the cobaltnickel-chromium PG-10K-01 coating $(1-$ ring cracks; 2 - regions of fretting wear).

На Рис. 5 представлены зависимости показаний вихретокового прибора от числа циклов нагружения, измеренные на пятнах контакта после контактноусталостных испытаний исследованного покрытия. Видно, что у покрытия ПГ-10К-01 для всех частот возбуждения вихретокового преобразователя зависимости показаний вихретокового прибора от числа циклов нагружения носят качественно одинаковый характер, при котором показания вихретокового прибора a сначала резко снижаются до $5 \times 10^{4}$ циклов нагружения. С увеличением числа циклов нагружения до $10^{5}$ наблюдается достаточно интенсивный рост величины $\alpha$, который затем сменяется ее менее интенсивным ростом до $3 \times 10^{5}$ циклов. При $5 \times 10^{5}$ циклов нагружения величина а снова демонстрирует резкое снижение, существенно более интенсивное, чем при $5 \times 10^{4}$ циклов. Дальнейшее нагружение до $8 \times 10^{5}$ сопровождается интенсивным ростом величины $\alpha$, который затем сменяется ее 


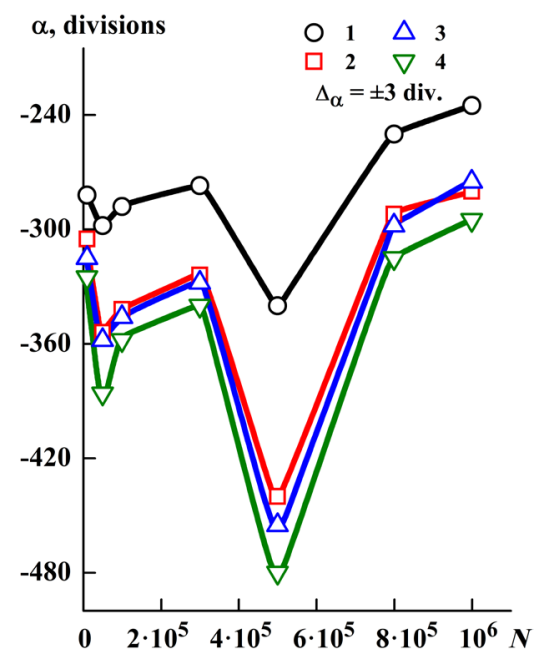

Pиc. 5. (Color online) Зависимости показаний вихретокового прибора а на частоте $f=36$ кГц (1), 72 кГц (2), 96 кГц (3) и 120 кГц (4) от числа циклов нагружения $N$, измеренные на пятнах контакта после контактно-усталостных испытаний кобальтхромоникелевого покрытия ПГ-10К-01.

Fig. 5. (Color online) Dependences of the eddy current device readings $\alpha$ at the frequency $f=36 \mathrm{kHz}$ (1), $72 \mathrm{kHz}$ (2), $96 \mathrm{kHz}$ (3) and $120 \mathrm{kHz}(4)$ on the number of loading cycles $N$, measured within contact spots after contact fatigue tests of the cobalt-nickelchromium PG-10K-01 coating.

менее интенсивным ростом вплоть до $10^{6}$ циклов. С повышением частоты возбуждения $f$ вихретокового преобразователя рассматриваемые зависимости становятся более выраженными.

Отмеченные для рассматриваемых покрытий отличия зависимостей показаний вихретокового прибора а от числа циклов нагружения при измерениях на различных частотах возбуждения $f$ вихретокового преобразователя обусловлены различной глубиной проникновения электромагнитного поля $\delta$ (чем больше $f$, тем меньше $\delta$ ) [33]. Оценка глубины проникновения электромагнитного поля $\delta$, выполненная с использованием подхода [27], показала, что толщина исследуемого слоя $\delta$ составила $\sim 2.6$ мм при минимальной частоте $f=36$ кГц и $\sim 1.4$ мм при максимальной частоте $f=120$ кГц. Это свидетельствует о том, что в поверхностных слоях более интенсивно развиваются процессы усталостной деградации, влияющие на физические характеристики покрытия. К факторам, которые могут оказывать влияние на характеристики $\mu$ и $\rho$, а, следовательно, и на показания вихретокового прибора исследованного покрытия, подвергнутого контактно-усталостному нагружению, относятся: трещинообразование, уплотнение покрытия из-за залечивания при деформировании содержащихся в нем несплошностей, рост плотности дислокаций. Образование на поверхности оксидных пленок и твердых растворов кислорода не оказывает существенного влияния на результаты электромагнитных измерений [17], а влияние на сигналы вихретокового преобразователя магнитной проницаемости и удельного электросопротивления стальной основы является постоянным при заданной частоте измерений.
Наблюдаемое резкое снижение показаний вихретокового прибора а у покрытия ПГ-10К-01 при увеличении числа циклов нагружения до $5 \times 10^{4}$ (см. Рис. 5) совпадает с ростом размера контактных повреждений и обусловлено образованием большого количества периферийных кольцевых трещин в зоне разрушения при когезионном скалывании покрытия (см. Рис. 4). Дополнительный вклад в уменьшение величины а также оказывает рост плотности дислокаций (механический наклеп), приводящий к снижению электропроводности покрытия (увеличению удельного электросопротивления) [17]. При увеличении количества циклов до $10^{5}$ наблюдаемый рост величины а у покрытия ПГ-10К-01 может быть обусловлен наблюдаемым экспериментально затиранием находящихся в зоне разрушения периферийных кольцевых трещин в процессе контактно-усталостных испытаний [28]. Затертые кольцевые трещины, по-видимому, уже не оказывают влияния на результаты вихретоковых измерений. Нагружение до $3 \times 10^{5}$ циклов сопровождается менее интенсивным ростом показаний вихретокового прибора $\alpha$, что обусловлено уплотнением данного покрытия. Уплотнение покрытия в результате залечивания несплошностей приводит к уменьшению его удельного электрического сопротивления [17]. Интенсивное снижение величины а при $5 \times 10^{5}$ циклов нагружения (см. Рис. 5), как и при числе циклов $5 \times 10^{4}$, совпадает с началом участка резкого роста размера контактных повреждений, и также обусловлено интенсивным трещинообразованием при когезионном скалывании покрытия. Дальнейшее нагружение до $8 \times 10^{5}$ циклов приводит к интенсивному росту величины $\alpha$, обусловленному затиранием трещин, а увеличение количества циклов вплоть до $10^{6}$ сопровождается менее интенсивным ростом показаний вихретокового прибора a, обусловленным продолжающимся уплотнением покрытия ПГ-10К-01.

Следовательно, трещинообразование и уплотнение покрытия ПГ-10К-01 при контактном нагружении оказывают сильное противоположное влияние на показания вихретокового прибора. Совокупное действие этих факторов и определяет характер зависимостей показаний вихретокового прибора а от числа циклов нагружения покрытия ПГ-10К-01 (см. Рис. 5). Следует также отметить наблюдаемую тенденцию к росту величины а у покрытия ПГ-10К-01 при увеличении количества циклов контактного нагружения несмотря на периодически повторяющиеся когезионное скалывание покрытия и соответствующее снижение показаний вихретокового прибора (см. Рис. 5). Это свидетельствует о том, что уплотнение покрытия в зоне контакта с индентором происходит непрерывно на протяжении всего процесса контактно-усталостного нагружения. Отметим, что рост величины а при $1 \times 10^{6}$ циклов относительно исходных значений более чем на порядок превышает погрешность измерения, то есть рост является значимым. Из Рис. 5 также видно, что при измерениях на частоте $f=36$ кГц величина а превышает исходные значения уже при $3 \times 10^{5}$ циклов. Однако в этом случае глубина проникновения электромагнитного поля $\delta \sim 2.6$ мм, что более чем в 2 раза превосходит толщину покрытия, 
и на показания вихретокового прибора существенное влияние оказывает ферромагнитная стальная основа.

\section{4. Выводы}

Исследована возможность использования вихретокового метода для контроля усталостной деградации при контактном нагружении кобальтхромоникелевого покрытия ПГ-10К-01, полученного методом газопорошковой лазерной наплавки. Показано, что контроль вихретоковым методом усталостной деградации при контактном нагружении покрытия ПГ-10К-01 возможен, однако имеет определенные ограничения вследствие немонотонного изменения показаний вихретокового прибора а от числа циклов нагружения. При этом с одной стороны, возможен контроль резкого роста размера контактных повреждений, который при данных условиях нагружения происходит при $5 \times 10^{4}$ и $5 \times 10^{5}$ циклов, и обусловлен образованием большого количества периферийных кольцевых трещин в зоне разрушения и соответствующим снижением величины а вследствие роста удельного электросопротивления покрытия. С другой стороны, возможен контроль достижения определенного числа циклов нагружения в диапазоне $8 \times 10^{5}-1 \times 10^{6}$, когда показания вихретокового прибора превысят исходные значения. Данный рост величины а обусловлен уплотнением покрытия в результате залечивания несплошностей и уменьшением его удельного электрического сопротивления. Контроль может проводиться измерениями показаний вихретокового прибора на больших частотах возбуждения вихретокового преобразователя $f=72-120$ кГц. В этом случае степень влияния ферромагнитной стальной основы на показания вихретокового прибора минимальна и анализируются преимущественно поверхностные слои, в которых более интенсивно развиваются процессы трещинообразования, механического наклепа, и уплотнения, оказывающие влияние на физические характеристики покрытия.

Благодарности/Acknowledgements. Работа выполнена в рамках государственных заданий ИМАШ УрО РАН по теме № АAАA-A18-118020790147-4 и ИФМ УрО РАН по темам «Структура», № АААА-А18-118020190116-6, u «Диагностика», № АААA-A18-118020690196-3. Механические испытания и электронная сканирующая микроскопия выполнены в ЦКП «Пластометрия» ИМАШ УрО РАН. Авторь выражают благодарность И.Ю. Мальгиной и А. Л. Осинцевой за нанесение покрытия методом лазерной наплавки. / This work was done within the state orders for IES UB RAS, reg. no. AAAA-A18-118020790147-4, and IMP UB RAS on the subjects "Structure", reg. no. AAAA-A18-118020190116-6, and "Diagnostics", reg. no. AAAA-A18-118020690196-3. The mechanical tests and SEM analysis were performed in CUC "Plastometriya" of the IES UB RAS. The authors are grateful to I. Yu. Malygina and A. L. Osintseva for preparing the coatings by means of laser cladding.

\section{Литература/References}

1. D.-G. Ahn. Int. J. Precis. Eng. Manuf. 14 (7), 1271 (2013). Crossref

2. C.L. Sexton, G. Byrne, K. G. Watkins. J. Laser Appl. 13 (1), 2 (2001). Crossref

3. J.R. Davis. ASM specialty handbook: heat-resistant materials. ASM International (1997) 591 p.

4. A. Amadeh, R. Ebadpour. J. Nanosci. Nanotechnol. 13 (2), 1360 (2013). Crossref

5. L.E. Afanasieva, G. V. Ratkevich. Letters on materials. 8 (3), 268 (2018). (in Russian) [Л.Е. Афанасьева, Г. В. Раткевич. Письма о материалах. 8 (3), 268 (2018).] Crossref

6. L.E. Falqueto, D. J. Butkus, J.D. B. De Mello, A.C. Bozzi, C. Scandian. Wear. 376 - 377 (B), 1739 (2017). Crossref

7. G. P. Rajeev, M. Kamaraj, S. R. Bakshi. Surf. Coat. Technol. 326 (A), 63 (2017). $\underline{\text { Crossref }}$

8. B. Ren, M. Zhang, C. Chen, X. Wang, T. Zou, Z.Hu. J. Mater. Eng. Perform. 26 (11), 5404 (2017). Crossref

9. E. A. Shur. Met. Sci. Heat Treat. 20 (8), 642 (1978). Crossref

10. L. I. Tushinskii, V.A. Bataev, V. M. Potapov, A.A. Bataev, A. P. Timofeev. Met. Sci. Heat Treat. 30 (5), 363 (1988). Crossref

11. A. Yonezu, B. Xu, X. Chen. Thin Solid Films. 518, 2082 (2010). Crossref

12. G. Ramírez, A. Mestra, B. Casas, I. Valls, R. Martínez, R. Bueno, A. Góez, A. Mateo, L. Llanes. Surf. Coat. Technol. 206, 3069 (2012). Crossref

13. G. Ramírez, E. Tarrés, B. Casas, I. Valls, R. Martínez, L. Llanes. Plasma Processes Polym. 6, S588 (2009). Crossref

14. E. Tarrés, G. Ramírez, Y. Gaillard, E. Jiménez-Piqué, L. Llanes. Int. J. Refract. Met. Hard Mater. 27, 323 (2009). $\underline{\text { Crossref }}$

15. I. A. Bataev, A.A. Bataev, M.G. Golkovski, D. S. Krivizhenko, A.A. Losinskaya, O. G. Lenivtseva. Appl. Surf. Sci. 284, 472 (2013). Crossref

16. R.A. Savrai, A.V. Makarov, N.N. Soboleva, I. Yu. Malygina, A. L. Osintseva. Obrabotka metallov (tekhnologiya, oborudovaniye, instrumenty). 4, 43 (2014). (in Russian) [P.А. Саврай, А.В. Макаров, Н.Н. Соболева, И.Ю. Малыгина, А.Л. Осинцева. Обработка металлов (технология, оборудование, инструменты). 4, 43 (2014).]

17. R. A. Savrai, A. V. Makarov, E. S. Gorkunov, L. Kh. Kogan, N.N. Soboleva, I. Yu. Malygina, A.L. Osintseva. Russ. J. Nondestr. Test. 51 (11), 692 (2015). Crossref

18. R.A. Savrai, A.V. Makarov, N.N. Soboleva, I. Yu. Malygina, A. L. Osintseva. J. Mater. Eng. Perform. 25 (3), 1068 (2016). Crossref

19. R. A. Savrai, A. V. Makarov, E. S. Gorkunov, N. N. Soboleva, L.Kh. Kogan, I.Yu. Malygina, A.L. Osintseva, N. A. Davydova. AIP Conf. Proc. 1915, 040049 (2017). Crossref

20. R.A. Savrai, A.V. Makarov, A.L. Osintseva, I. Yu. Malygina. J. Mater. Eng. Perform. 27 (2), 601 (2018). $\underline{\text { Crossref }}$ 
21. R. A. Savrai, A. V. Makarov. Mat. Sci. Eng. A. 734, 513 (2018). Crossref

22. R. A. Savrai. Phys. Met. Metallogr. 119 (10), 1013 (2018). Crossref

23. R. A. Savrai, A. V. Makarov, E. S. Gorkunov, N. N. Soboleva, L. Kh. Kogan, I. Yu. Malygina, A. L. Osintseva. AIP Conf. Proc. 2053, 040088 (2018). Crossref

24. F. Shu, Z. Tian, H. Zhao, W. He, S. Sui, B. Liu. Mater. Lett. 176, 306 (2016). $\underline{\text { Crossref }}$

25. A.V. Makarov, R.A. Savrai, A.L. Osintseva, I. Yu. Malygina. Izvestiya Chelyabinskogo nauchnogo tsentra. 2, 28 (2009). (in Russian) [А.В. Макаров, Р.А. Саврай, А.Л. Осинцева, И.Ю. Малыгина. Изв. ЧНЦ. 2, 28 (2009).]

26. R. Liu, S. Q. Xi, S. Kapoor, X. J. Wu. Int. J. Res. Rev. Appl. Sci. 5 (2), 110 (2010).

27. A. V. Makarov, E. S. Gorkunov, I. Yu. Malygina, L. Kh. Kogan, R.A. Savrai, A.L. Osintseva. Russ. J. Nondestr. Test. 45 (11), 797 (2009). Crossref
28. R. A. Savrai, N.N. Soboleva, I. Yu. Malygina, A.L. Osintseva. Opt. Laser Technol. 126, 106079 (2020). Crossref

29. A.V. Makarov, E.S. Gorkunov, L.Kh. Kogan. Russ. J. Nondestr. Test. 43 (1), 21 (2007). Crossref

30. A.S. Bakunov, V.F. Muzhitskii, S.E. Shubochkin. Russ. J. Nondestr. Test. 40 (5), 346 (2004). Crossref

31. Patent RF № 162959, 2016. (in Russian) [Патент РФ № 162959, 2016.]

32. V.V. Dyakin, V.A. Sandovskiy. Teoriya i raschet nakladnykh vikhretokovykh preobrazovateley. Moscow, Nauka (1981) 136 p. (in Russian) [В.В. Дякин, B.А. Сандовский. Теория и расчет накладных вихретоковых преобразователей. Москва, Наука (1981) 136 c.]

33. A.L. Dorofeev. Induktsionnaya strukturoskopiya. Moscow, Energiya (1973) 176 p. (in Russian) [А.Л. Дорофеев. Индукционная структуроскопия. Москва, Энергия (1973) 176 с.] 